\title{
Dos Comentarios de 1915 Sobre Los de abajo
}

En su empeño por trazar la historia de la novela Los de abajo, los estudiosos han tenido poco éxito en determinar los detalles de su recepción en EI Paso, Texas, durante las semanas que siguieron a su publicación en las postrimerías de 1915. Sólo el autor Mariano Azuela ha proporcionado unos cuantos detalles respecto de la suerte de su novela durante este período y éstos demuestran un pesimismo consistente sobre el asunto. Por ejemplo, se observa una reacción de inquietud ante la hostilidad expresada por oficiales villistas de la guarnición de Cuidad Juárez, la ciudad fronteriza frente a $\mathrm{El} \mathrm{Paso.}{ }^{1} \mathrm{El}$ autor también se siente desanimado ante la aparente falta de entusiasmo por el modesto tomo, que se ve reflejada en su poca o nula venta en las librerías y puestos de revistas de El Paso. ${ }^{2}$ La única nota optimista introducida por Azuela es la escena en que lee Los de abajo a un grupo de compatriotas que se han reunido en un cuarto de hotel una noche de noviembre de $1915 .^{3}$ Son amigos y conocidos de la misma categoría del autor, es decir, refugiados políticos y militares que por un motivo u otro han abandonado su país. Aquí la única reacción que revela Azuela es la de su compañero en armas Manuel Caloca, quien se identifica como Demetrio Macías de la novela cuando los compañeros conducen al herido en camilla por el fondo del cañón de Juchipila.

En relación con un estudio más amplio y detallado sobre las ediciones de Los de abajo aparecidas en El Paso, estudio que tengo en preparación, he tenido hace no mucho tiempo, la oportunidad de consultar una colección bastante amplia de El Paso del Norte, el diario de lengua española que publicó la novela de Azuela en folletín. Las columnas de este periódico del mes de diciembre de 1915 contienen dos cortos comentarios relativos a Los de abajo que sin duda son las primeras observaciones no azuelianas sobre esta obra que hasta la fecha se conocen. En febrero de 1920 Francisco Monterde publicó en Biblos un reconocimiento del mérito de Los de abajo que se

1 Mariano Azuela, en carta dirigida a L. B. Kiddle, 10 noviembre de 1948. En Epistolario y archivo, edición de Beatrice Berler (México, 1969), p. 140.

2 Mariano Azuela, 'El novelista y su ambiente," en Obras completas (México, 1960), III, 1088.

3 Obras completas, III, 1081-1082: 
ha considerado como tal vez el principio de la crítica literaria sobre esta novela. ${ }^{4}$ Pero este comentario no se funda en las ediciones de El Paso sino en el texto cuidadosamente revisado por Azuela y publicado por su amigo Razaster. Lo mismo puede decirse del " descubrimiento" de la obra por literatos mexicanos y su cambio de puntos de vista sobre ella, que no se hicieron sino hasta fines de 1924 y principios de $1925 .{ }^{5}$ Las piezas aparecidas en El Paso del Norte, por consiguiente, anticipan las actividades ya mencionadas y son significativas porque presentan los pareceres y las reacciones de hombres que habían desempeñado papeles activos en la Revolución mexicana. ${ }^{6}$

La primera de éstas se titula sencillamente "Los de abajo" y se encuentra en el número que corresponde al viernes, 10 de diciembre de 1915 , llevando como firma las letras "E. A. P."7 El autor es Enrique Pérez Arce, identificado por Azuela como uno de los amigos a quienes leyó Los de abajo en el cuarto de hotel en El Paso una noche de noviembre. Como ya los había hecho Mariano Azuela, Pérez Arce hizo sus estudios en Guadalajara, primero en el Liceo de Varones y después en la Escuela de Jurisprudencia. Todavía era estudiante cuando estallaron las actividades revolucionarias en el estado de Jalisco en 1910 y fue uno de los que activamente formaron un partido político estudiantil en conjunto con Ignacio Ramos Praslow y los hermanos Roque y Enrique Estrada. Todos éstos después llegaron a ser figuras activas en la Revolución en Jalisco. ${ }^{8}$

Pérez Arce emprende su comentario sobre la novela de Azuela desde el punto de vista de un amigo y correligionario. Expresándose en un estilo que falta poco para llegar a preciosismo, revela una comprensión de la personalidad del novelista y su manera poco ostentosa de preparar y presentar una obra literaria, en una combinación de una extrema modestia con un evidente mérito artístico: "De puntillas, sin que nadie lo sienta, el Dr. Azuela llega a la ventana lírica del arte, deja ahi furtivamente un puñado de rosas frescas, y luego torna a su viejo retiro silencioso." La perspectiva de Pérez Arce no se limita a Los de abajo; ha leído obras anteriores de Azuela o demuestra familiaridad con ellas, pues menciona específicamente Maria Luisa, Los fracasados y Mala yerba.

Por medio de una frase califica a cada una de éstas y luego enfoca sobre Los de abajo, "que es la cristalización de las escenas de la actual Revolución Mexicana." Nota personajes, tipos y episodios, presentando en seguida una florida recreación de los paisajes que sirven como el fondo contra el cual se mueven los personajes. A pesar de una preocupación constante por su propio estilo, Pérez Arce no pierde de vista la actitud de Mariano Azuela ante la Revolución y la suerte de los de abajo que se hallan arrebatados por el conflicto: "Y en el fondo de todos los paisajes, como queriendo inluminar(sic)los corazones, la lucecita azul del ensueño patriótico, del ideal

\footnotetext{
${ }^{4}$ Sobre Los de abajo, en Biblos [México], II, 59 (28 de febrero de 1920), p. 35. Se reproduce en Epistolario y arcbivo, p. 268.

${ }^{5}$ Véase John E. Englekirk, "The Discovery of Los de abajo by Mariano Azuela," Hispania, XVIII (1935), 53-62.

${ }^{6}$ No hay mención de ellas en la extensa bibliografía preparada por Luis Leal e incluída en su Mariano Azuela : vida y obra (México.1961), pp. 135-168, ni en el tomo Epistolario yrarchivo citado arriba.
}

${ }^{7}$ El Paso del Norte, El Paso, Texas, viernes 10 de diciembre de 191), Número 1801, p. 4. Pertenece a la Epoca II, Tomo VIII. Esta cita es aplicable a cualquier mención del artículo de Pérez Arce.

${ }^{8}$ José Guadalupe Zuno, Historia de la Revolución en el Estado de Jalisco (México, 1964), p. 57. Pérez Arce en años posteriores llegó a ser gobernador del estado de Sinaloa, México. 
político, de la justificación de estas santas rebeldías del pueblo esclavizado...!" Tomando en cuenta los antecedentes políticos de Pérez Arce y su experiencia en el ramo, éste presta relativamente poca atención a los rasgos ideológicos de Los de abajo. Esto resulta extraño, dada la importancia que les presta el novelista.

A la vez Pérez Arce esquiva una evaluación directa del estilo de Los de abajo, prefiriendo ceder esa tarea a "plumas doctorales," pero esta aseveración no le impide observar que en algunas páginas hay necesidad de pulimento, que algunos personajes en lo psicológico no son verdaderos, y que en general la obra posee defectos que deben corregirse. A pesar de estas observaciones negativas su reacción generalmente es favorable:

Pero quien glosa estas líneas...se reduce a dejar estampada aquí su impresión, y como de todas maneras juzga que el esfuerzo es noble y superior a todos los semejantes que han atestado los escaparates de folletos sin alma y sin arte, reciba un cordial y entusiasto aplauso el inteligente y modesto autor.

El segundo artículo también se titula "Los de abajo." Lleva la firma de J. Jesús Valadez y salió publicado en el número correspondiente al martes, 21 de diciembre de 1915. ${ }^{9}$ Las actitudes expresadas por Valadez difieren poco de las que ya habia anotado Pérez Arce, aunque se demuestra mucho más entusiasta. Su evaluación inicial de Los de abajo viene al grano: "La obra del señor Azuela es sencillamente magistral." (p. 2) Valadez se refiere específicamente a los rasgos populares que dominan en la novela, en particular el habla popular, y pone de relieve el papel que desempeña el hombre ordinario en el conflicto que todavia sacude a México:

Por ella pasan, como por una película fantástica, todas las peripecias de las guerrillas formadas por nuestros hombres del pueblo, los más perseguidos, los más explotados y escarnecidos por las pasadas y brutales tiranias, que por fin han logrado sacudir aquellos, a costa de tantos y tan cruentos sacrificios. (pp. 2-3)

En este respecto, Valadez demuestra una clara simpatía con la actividad del mismo Azuela en la Revolución y su preocupación por la suerte de los de abajo, “...porque él no ha sabido encerrarse en esa indiferencia criminal de los que injustificadamente se titulan 'neutrales' ante los dolores de los que sufren por reconquistar sus perdidas libertades.' (p. 3)

Valadez reacciona de la misma manera que los lectores posteriores de Los de abajo. El manifiesta admiración por la majestuosa escena de la última batalla en el cañón donde la muerte alcanza a Demetrio. Cita los párrafos finales del libro ${ }^{10}$ y alaba a Azuela por su hábil manejo de este episodio que califica de "verdaderamente digno de un canto homérico!" (p. 3)

9 El Paso del Norte, martes 21 de diciembre de 1915, Número 1810, pp. 2-3.

${ }^{10}$ Los de abajo (E1 Paso, Texas, 1916), p. 143. 
En aquellos trozos de sus memorias que tienen que ver con los meses que vivió en El Paso, Mariano Azuela no hace alusión a J. Jesús Valadez. Este es el autor de dos poesias que aparecieron en las columnas de El Paso del Norte durante noviembre de 1915. Parece dudoso que Valadez fuera refugiado y de las mismas condiciones transitorias de Azuela, Pérez Arce, Manuel Caloca y los demás compañeros de éstos. Más bien da indicios de ser residente establecido en El Paso o Ciudad Juárez.

En sus artículos retrospectivos Azuela se mantiene callado en cuanto a estas evaluaciones de Los de abajo contribuidas por Pérez Arce y Valadez. No se les ha dado sitio en las bibliografías que registran las obras del novelista y la crítica que se ha hecho sobre ellas. Dadas las condiciones de desorden existentes en el norte de México durante el mes de diciembre de 1915 y lo transitorio de la permanencia de Azuela en El Paso, uno se pregunta si alguna vez Mariano Azuela se dio cuenta de la existencia de estos artículos. En vista de la fecha en que fue publicado, parece muy probable que no sólo tenía conocimiento del comentario de Pérez Arce sino que también pudo haberlo leído en El Paso del Norte. A la vez es de dudarse que llegaran a su atención las palabras de Valadez, que se dieron a la prensa diez días después. Ya para aquella fecha Azuela procuraba hallar la manera de regresar a México y la oportunidad no tardó en presentarse. El mismo día en que se dieron a luz las observaciones de Valadez, los grandes títulos de la primera plana de El Paso del Norte proclamaban la rendición de la guarnición villista de Cuidad Juárez y la toma de posesión por tropas carrancistas bajo el mando del general Treviño. Esta transición se efectuó el 20 de diciembre. El mismo Azuela ha informado que se aprovechó de la confusión existente durante las primeras horas después de la entrada de los carrancistas para deslizarse sobre el puente internacional y entrar en territorio mexicano como el primer paso de su viaje de regreso a Guadalajara donde lo esperaban su mujer y sus hijos." $\quad$ El anhelo del novelista en esta situación fue la reunión con su familia y la oportunidad de reanudar el hilo de su vida en México en condiciones de tranquilidad. Así que los intereses literarios en aquellos días sólo pudieron tener un valor secundario para Mariano Azuela.

Durante el mes de diciembre en El Paso del Norte apareció una serie de anuncios que informaban al público que se vendían ejemplares de Los de abajo. Aunque este aviso fue preparado en las oficinas de la misma imprenta que había publicado el libro, las palabras contenidas en él constituyen en cierto sentido una evaluación crítica de esta obra de Azuela:

Esta novela es el trasunto más fiel de la contienda civil en México. Su autor no adula a ninguno de los partidos políticos y con la verdad desnuda flagela el crimen y la injusticia en donde quiera que lo encuentra, sin restricciones ni piedad alguna. ${ }^{12}$

Este breve anuncio que mide apenas unas cuatro pulgadas de largo proporciona pocos datos más, pero sí agrega que se mandará libre de porte un ejemplar de Los de abajo al recibir la cantidad de treinta centavos de dólar, suma que puede ser remitida en sellos de correo, por giro postal o express. Está de venta también en la oficina de El Paso del Norte, 609 Sur de la Calle Oregon, El Paso. No extraña que esta novela de Mariano Azuela sea

${ }^{11}$ Obras completas, III, 1088.

${ }^{12}$ El Paso del Norte, domingo 5 de diciembre de 1915, Número 1797, p. 4. 
objeto de alabanzas en una exposición cuyo propósito es fomentar la venta del libro indicado. Sin embargo, en años posteriores literatos y críticos han escrito sobre Los de abajo en términos comparables. A pesar de la fuerte inclinación carrancista de El Paso del Norte, que con frecuencia hace uso de expresiones virulentas en sus reportajes sobre los contrarios de Venustiano Carranza, el anuncio de la novela es eminentemente justo y hasta favorable para con Azuela. En vista de los relatos de éste sobre sus experiencias en El Paso y la publicación de Los de abajo, es poco probable que Fernando Gamiochipi, el director del diario, no tuviera noticia de la actuación del novelista como médico con las fuerzas villistas en Jalisco. En las páginas de El Paso del Norte no hay indicación alguna en cuanto a la persona que preparó el anuncio. Si no fue Gamiochipi es evidente que dio su aprobación y permitió que se publicara.

A la vez es posible sacar otras conclusiones a base de la aparición del anuncio. Hay una clara indicación de que Fernando Gamiochipi promovió la venta de Los de abajo en las columnas del diario que dirigía. El aviso apareció por primera vez el domingo 5 de diciembre de 1915 y fue repetido en casi todos los números que quedaban del mes. Sin embargo, los resultados alcanzados no enriquecieron al autor, quien ha comentado que después de un mes de estar de venta se habían vendido sólo cinco ejemplares. En un sentido, hay que descontar las palabras de Azuela, quien salió de El Paso de regreso para Guadalajara unos quince días después de que se informó en $E l$ Paso del Norte que se vendía la novela.

De más significancia es la posibilidad de precisar la fecha en que apareció Los de abajo en forma de libro. Hasta la fecha los únicos indicios han sido los que se dan en el libro mismo y éstos son contradictorios. En la cubierta se lee "November 1915" pero en la portada se da como "1916." Si en el diario se anunció el 5 de diciembre que había ejemplares para la venta, entonces la novela apareció en aquella fecha o unos días antes. En su comentario del 21 de diciembre, J. Jesús Valadez declaró en términos explícitos que Mariano Azuela le había regalado un ejemplar y sin duda Enrique Pérez Arce ya poseía uno también.

El libro que inspiró las palabras de Pérez Arce y Valadez es la versión de Los de abajo que Azuela terminó precipitadamente en El Paso, entregando en seguida el manuscrito al primer editor que aceptara pagarle algo, y esto con el propósito de tener que comer durante la permanencia del novelista en territorio norteamericano. No es el texto refinado y pulido que preparó Azuela en condiciones más favorables después de haberse establecido en la capital de México en 1916. Este no salió publicado sino hasta principios de 1920. ${ }^{13}$ Este hecho parece explicar los "defectos" observados tanto por Pérez Arce como Valadez en El Paso del Norte. La revisión bastante amplia efectuada por el autor en años posteriores revela la posición de Azuela ante esta' primera versión de su libro, que en ciertos aspectos y algunos capítulos debía fortalecerse. En El Paso no tenía suficiente tiempo ni existía el ambiente para tal empresa, pero esta situación no impidió que comunicara a sus amigos, a Pérez Arce en particular, la premura con que había preparado esa versión inicial de Los de abajo y los puntos débiles que de esa premura habian resultado.

${ }^{13}$ Los de abajo (México, 1920). Esta edición fue producto de la Imprenta "Razaster." Leal la considera la quinta de esta novela, op. cit., p. 135. 
Sin embargo, los dos comentaristas asumen una actitud favorable ante Mariano Azuela. Hallan agradable su novela y en general la alaban, aunque casi siempre en términos subjetivos Suya es la expresión crítica sobre Los de abajo de fecha más temprana que poseemos, piezas precursoras que reflejan los pareceres de hombres que todavía observaban la Revolución mexicana desde cerca, tanto en la dimensión del tiempo como del espacio. La sangrienta lucha entre las fuerzas de Venustiano Carranza y Francisco Villa se aproximaba a su conclusión y su angustia final pudo observarse en el extremo norte de México al otro lado del Río Grande. La perspectiva de Pérez Arce y J. Jesús Valadez no fue la de los críticos metropolitanos que emprendieron el intercambio de opiniones sobre Los de abajo durante la controversia de 1924-1925. Los dos amigos de Azuela tuvieron la fortuna de coincidir en el mismo sitio y el momento oportuno, es decir, en El Paso cuando llegó el novelista pasando el puente internacional llevando en sus manos el manuscrito de Los de abajo, todavía sin terminar.

University of California, Los Angeles

STANLEY L. ROBE 